\title{
The effectiveness of neuroendoscopic versus non-neuroendoscopic procedures in the treatment of lateral ventricular cysts: a retrospective medical record review study
}

\author{
Peng Zhao ${ }^{1}$, Xinsheng Wang ${ }^{1}$, Chuzhong $\mathrm{Li}^{2}$, Songbai Gui ${ }^{1}$, Xuyi Zong ${ }^{1}$ and Yazhuo Zhang ${ }^{2 *}$
}

\begin{abstract}
Background: The aim of this study was to assess the effectiveness of neuroendoscopy compared with nonneuroendoscopic procedures for treating patients with arachnoid membrane cysts in the lateral ventricles.

Methods: The medical records of 28 patients with arachnoid membrane cysts in the lateral ventricles who were treated with neuroendoscopy and 39 such patients treated with non-neuroendoscopic techniques using classic treatment procedures were reviewed. The neuroendoscopic approach combined craniotomy, corticectomy, lesion resection and cyst ventriculostomy or cyst cisternostomy to restore normal cerebrospinal fluid circulation. The nonneuroendoscopic techniques included craniotomy, corticectomy, and lesion resection performed under a microscope. Clinical outcomes of symptoms and cyst size change on imaging were compared between the two treatment groups during follow-up (range: 1-5 years).

Results: Patients in the neuroendoscopy group had significantly less blood loss $(P<0.001)$ and shorter operative time $(P<0.001)$, better marked improvement in symptoms (64.3\% vs. $5.1 \%$, respectively), and a higher total resection rate $(92.9 \%$ vs. $66.7 \% ; P=0.011)$ compared with the patients in the non-neuroendoscopy group. In the neuroendoscopy group there was no cyst recurrence whereas in the non-neuroendoscopy group 8 (20.5\%) patients had cyst recurrence. However, all patients in the neuroendoscopy group had postoperative transient fever and 8 (28.6\%) patients had subdural fluid accumulation which was treated and subsequently resolved during follow-up. These symptoms did not occur in the non-neuroendoscopy group.

Conclusion: We found that neuroendoscopic therapy for arachnoid cysts in the lateral ventricles was more efficacious than non-neuroendoscopic methods. Our results indicate that neuroendoscopy may produce better clinical outcomes than non-neuroendoscopic procedures in treating patients with arachnoid cysts in the lateral ventricles.
\end{abstract}

Keywords: Neuroendoscope, Lateral ventricle, Arachnoid cyst, Intracranial lesion

\section{Background}

Neuroendoscopy plays an important role in the diagnosis and treatment of a variety of lesions, especially cystic intracranial lesions, both in pediatric and adult patients [1,2]. Cysts are particularly amenable to the neuroendoscopic approach because they are not difficult to aspirate and their walls are easy to ablate or resect $[3,4]$. This group of space-

\footnotetext{
*Correspondence: kosinmed@163.com

${ }^{2}$ Beijing Neurosurgical Institute, Capital Medical University, Beijing 100050,

People's Republic of China

Full list of author information is available at the end of the article
}

filling lesions includes colloid, arachnoid, porencephalic, and pineal cysts, as well as Rathke's cleft cysts, cystic craniopharyngiomas, and malignant tumors with cystic components $[2,5]$. Neuroendoscopy can be used to excise or reduce the volume of the cyst or as palliative treatment $[3,6]$. Neuroendoscopy has the advantage of being less invasive than non-neuoendoscopic surgical procedures and is associated with reduced morbidity and mortality and fewer complications, shorter hospital stays, and faster return to work compared with other neurosurgical techniques [2,3,5-8]. Neuroendoscopic techniques can

\section{Biomed Central}

(c) 2013 Zhao et al.; licensee BioMed Central Ltd. This is an Open Access article distributed under the terms of the Creative Commons Attribution License (http://creativecommons.org/licenses/by/2.0), which permits unrestricted use, distribution, and reproduction in any medium, provided the original work is properly cited. 
provide simultaneous treatment of hydrocephalus with cyst or resection, thereby avoiding additional invasive procedures [7].

Arachnoid cysts, colloid cysts, and tumors in the lateral ventricles occur frequently and account for about $30 \%$ of all intracranial lesions [9-11]. Neuroepithelial cysts in the lateral ventricles are often located in the trigone area, temporal horn, or posterior horn. There have been only a few studies (which included about 10-20 patients) that assessed the use of neuroendoscopy for treating lateral ventricular cysts [12-15]. All patients in this study had arachnoid membrane cysts. These cysts are filled with fluid that is similar to but not the same as cerebrospinal fluid [16]. The cysts are formed from duplication or spitting of the arachnoid layer [16]. Because these cysts are located in the lateral ventricles they block the cerebrospinal fluid circulation route, thereby producing elevated intracranial pressure. Therefore, surgery is required. The purpose of this study was to retrospectively analyze the clinical outcomes of neuroendoscopic surgery versus non-neuroendoscopic surgical methods for patients with arachnoid membrane cysts in the lateral ventricles.

\section{Methods}

\section{Patients, examinations, clinical data}

This was a retrospective medical record review study that was performed according to the Declaration of Helsinki. The study was approved by the Ethical Review Board of Beijing Tiantan Hospital. The medical records of patients who had cysts located in the lateral ventricles and were enrolled from the Neurosurgical Department of Beijing Tiantan Hospital from March 2005 to May 2011 were reviewed. Patients diagnosed with arachnoid membrane cysts in the lateral ventricles and treated surgically either by neuroendoscopy or non-neuroendoscopic methods were selected. The patients were operated on to relieve the symptoms, resect the lesions, and alleviate high intracranial pressure caused by hydrocephalus. Data were included from clinical history, physical examination, CT and/or MRI scans, surgery, pathological findings, and follow-up.

\section{Surgical method}

All operations were performed through the arachnoidventricular space. The selection of the appropriate surgical incision was based on the location of the cyst in the lateral ventricle. For neuroendoscopy, a parietal-occipital straight incision was made for cysts in the trigone area of the lateral ventricle, and a temporal straight incision was typically made for cysts in the posterior horn or temporal horn of the lateral ventricle. A temporal straight incision was made at the nearest site to the posterior horn or temporal horn of the lateral ventricle, which resulted in minimal invasive cutting.
The skull in the surgical region was drilled and a 2-cm bone flap was created. Then corticectomy was performed and the ventricle was punctured. A multi-channel rigid endoscope (Rudolf Medical, Fridingen, German) with an external diameter of $8 \mathrm{~mm}$ was inserted into the ventricle. To remove the cyst, a bipolar coagulator, biopsy forceps, and microscopic scissors were inserted into the cavity and the cyst was gently pulled out and removed gradually in small pieces. Using this strategy, combined with water-jet resection, the cyst wall was almost totally removed. Care was taken in removing the cysts as they were often adhered to the choroid plexus, and the force of removal could cause intracerebroventricular hemorrhage. Unresectable areas were coagulated to prevent recurrence. The lateral ventricle was irrigated with room temperature saline to remove any remaining unattached cyst wall or other tissue remnants.

According to the clinical symptoms, patients in the non-neuroendoscopy group were treated with classic methods such as microscopic surgery including craniotomy, corticectomy, and lesion resection for cyst resection. The incision was made in the same location as in the neuroendoscopic procedure but the incision had to be long enough to expose the lesion. The burr hole was enlarged to a keyhole craniotomy of about $3-3.5 \mathrm{~cm}$. Under the microscope the membrane was then fenestrated or partially resected.

\section{Follow-up}

Patients were followed up from 1 to 5 years. All patients underwent $\mathrm{CT}$ and/or MRI scans 3 months after being discharged. The scans were used to evaluate patient outcome. Improvement was categorized as markedly improved (i.e., symptoms were alleviated and the cyst was either reduced in size or absent); improved (i.e., symptoms were alleviated, but there was no change in cyst size); or no effect (i.e., symptoms were unchanged and the cyst size was the same or, larger, or the number of cysts had increased) [17].

\section{Statistical analysis}

Comparability between the two groups was determined using the Mann-Whitney $U$ test for skewed continuous variables and a chi-square/Fisher's exact test for categorical variables. Data are presented as the median (interquartile range) for continuous data and numbers (percentages) for categorical data. All statistical assessments were two-sided and evaluated at the 0.05 level of significant difference. Statistical analyses were performed using SPSS 15.0 statistics software (SPSS Inc, Chicago, IL).

\section{Results}

Patient demographics and disease characteristics

Baseline patient demographics were similar between the neuroendoscopy group $(n=28)$ and the non-neuroendoscopy 
group $(\mathrm{n}=39)$ in age and cyst location (all $P>0.05$ ) (Table 1). However, there was significant difference in gender and the cyst size between the two groups $(P<0.005)$. For both treatment groups, the most common symptoms at presentation were headache and/or vomiting.

Figure $1 \mathrm{~A}$ and $\mathrm{B}$ show neuroendoscopic views of a lateral ventricular cyst and Figure $1 \mathrm{C}$ shows the resected cyst from a lateral ventricle. Magnetic resonance images of lesions in the lateral ventricle before the operation and 3 months after the operation were obtained regularly (Figure 2). In the pathological examination, cystic wall-like tissue was confirmed (Figure 3).

\section{Surgical outcomes}

Median follow-up duration in both groups was 2 years. In the neuroendoscopy group, $18(64.3 \%)$ and 8 (28.6\%) patients had marked improvement and improvement in symptom alleviation, respectively, while in the nonneuroendoscopy group, 2 (5.1\%) and 24 (61.5\%) patients

Table 1 Patient demographics and baseline characteristics

\begin{tabular}{|c|c|c|c|}
\hline & $\begin{array}{c}\text { Neuroendoscopy } \\
\text { group }(n=28)\end{array}$ & $\begin{array}{c}\text { Non-neuroendoscopy } \\
\text { group }(n=39)\end{array}$ & P-value \\
\hline$\overline{\text { Age }(\text { year) }}{ }^{1}$ & $15(9,37)$ & $12(7,25)$ & 0.712 \\
\hline Gender, n (\%) & & & $0.018^{*}$ \\
\hline Male & $7(25.0)$ & $21(53.8)$ & \\
\hline Female & $21(75.0)$ & $18(46.2)$ & \\
\hline Location, n (\%) & & & 0.810 \\
\hline $\begin{array}{c}\text { Left lateral } \\
\text { ventricle body }\end{array}$ & $7(25.0)$ & $12(30.8)$ & \\
\hline $\begin{array}{r}\text { Right lateral } \\
\text { ventricle body }\end{array}$ & $16(57.1)$ & $16(41.0)$ & \\
\hline $\begin{array}{l}\text { Left lateral } \\
\text { ventricle trigone } \\
\text { area }\end{array}$ & $2(7.1)$ & $7(17.9)$ & \\
\hline $\begin{array}{l}\text { Right lateral } \\
\text { ventricle trigone } \\
\text { area }\end{array}$ & $2(7.1)$ & $4(10.3)$ & \\
\hline $\begin{array}{l}\text { Septum } \\
\text { pellucidum }\end{array}$ & 1 (3.6) & $0(0.0)$ & \\
\hline Cyst size $\left(\mathrm{cm}^{2}\right)^{1}$ & $6(2,6)$ & $6(6,12)$ & $0.002^{*}$ \\
\hline \multicolumn{4}{|l|}{ Symptoms, n (\%) } \\
\hline Headache & $16(57.1)$ & $25(64.1)$ & 0.617 \\
\hline Vomiting & $16(57.1)$ & $25(64.1)$ & 0.617 \\
\hline Double vision & $2(7.1)$ & $0(0.0)$ & 0.171 \\
\hline $\begin{array}{l}\text { Intelligence } \\
\text { decline }\end{array}$ & $4(14.3)$ & $2(5.1)$ & 0.227 \\
\hline Paresis & $3(10.7)$ & $0(0.0)$ & 0.068 \\
\hline
\end{tabular}

had marked improvement and improvement in symptom alleviation, respectively. Patients in the neuroendoscopy group had significantly less blood loss and shorter operative time than those in the non-neuroendoscopy group (both $P<0.001$ ) (Table 2). But, more patients in the neuroendoscopy group had post-operative fever and subdural fluid accumulation than in the nonneuroendoscopy group $(P<0.001)$. Postoperative fevers in the neuroendoscopy group were non-infectious based on cerebrospinal fluid (CSF) exam and culture, and were most likely the result of intracerebroventricular rinsing during surgery. The fevers resolved after conservative treatment. The subdural fluid was absorbed within 3 months. One patient in the neuroendoscopy group had an intracerebroventricular hemorrhage during surgery which was treated by craniotomy and intracerebroventricular hematoma evacuation. There were no cases of cyst recurrence in the neuroendoscopy group whereas in the non-neuroendoscopy group there were 8 cases $(20.5 \%)$ of cyst recurrence.

There was no significant difference of outcomes in the duration of follow-up time between patients treated with neuroendoscopic and non-neuroendoscopic methods $(P=0.330)$ (Table 2). Patients in the neuroendoscopy group compared with patients in the non-neuroendoscopy group had a higher total resection rate $(92.9 \%$ vs. $66.7 \%$, respectively; $P=0.011$ ).

In the neuroendoscopy group, there was one case in which the symptoms were not relieved following cyst resection 6 months after the operation. This patient underwent a ventriculoperitoneal shunt operation. There were no deaths in either treatment group.

\section{Discussion}

Prior studies have indicated that neuroendoscopy is a safe and effective method for treating patients with intracranial cysts [1,18-22]. However, only a few studies have investigated the use of neuroendoscopy for treating cysts located in the lateral ventricles [12-15]. In this study, patients treated with neuroendoscopy had generally better clinical outcomes than patients treated with non-neuroendoscopic procedures. The total resection rate was higher for neuroendoscopy versus non-neuroendoscopy $(P<0.05)$. We attribute this to the endoscopic approach improving visualization in tight spaces, especially within the lateral ventricle, and to the degree of freedom in creating surgical corridors, etc. Neuroendoscopy was also associated with less operation-related blood loss, shorter surgical time, and greater improvement in symptoms compared with nonneuroendoscopy. Moreover, the proportion of patients with post-operative hydrocephalus was higher in the nonneuroendoscopy group.

Neuroendoscopy is an important option for the treatment of intracranial cysts. Microsurgical approaches that 
Figure 1 Endoscopic views of (A) an arachnoid membrane cyst located at the body of the lateral ventricle and (B) adhesion between the intracerebroventricular cyst and the choroid plexus. The cyst was resected from the lateral ventricle (C).

include craniotomy and fenestration, and cystoperitoneal shunting are valuable techniques, however, endoscopy which allows closer direct cyst or tumor visualization, is less invasive, and decreases severe complications associated with other surgical methods. These properties are particularly important in treating young patients with different types of benign tumors [1,21]. Neuroendoscopy has been recommended as the first choice of therapy for treating intracranial cysts $[8,18,21-23]$, including cysts located in the lateral ventricles [12,24]. It has been recommended that when the manipulations are done through the endoscope that neuroendoscopy is best performed on deep-seated cysts such as those in the lateral ventricles as it is relatively less traumatic to the brain parenchyma and provides good visualization [24]. Also, once the endoscope is fixed in position, instruments and optics can be changed readily without damage to brain structures along the approach. Also, endoscopic cyst fenestration from the lateral or third ventricle based on cyst extension presents no risk with regard to damaging the deep incisural and quadrigeminal veins [25]. A disadvantage of this method is the limited range of motion and the size of the instruments that fit into the working channel of the endoscope [24]. Our study supports the idea of removing cysts located in the lateral ventricles by neuroendoscopy where cyst removal is performed through the endoscope itself. In our study, no patients treated with neuroendoscopy had cyst recurrence while cysts recurred in $20.5 \%$ of patients treated by non-neuroendoscopic techniques. Gangemi et al. reported that neuroendoscopy was associated with a greater frequency of cyst recurrence compared with other surgical techniques [25]. Our results differed. The reason for this difference is not clear. We used rigid neuroendoscopy to resect arachnoid membrane cysts in the lateral ventricles. Rigid neuroendoscopy was also reported to have been used successfully for the treatment of cerebral aneurysms [26] and colloid cysts [8]. Successful use of flexible neuroendoscopy has been reported for the treatment of supracellar arachnoid cysts [27] and shunt malfunction [28].

Our findings are mostly similar to those of other studies that compared the efficacy and safety of neuroendoscopy to microsurgical resection in treating intraventricular cysts. Several studies reported that neuroendoscopy resulted in less morbidity and shorter hospital stay for adults and children, and more rapid return of the patients to work $[5-8,15,18]$. King and colleagues reported their experiences with endoscopic resection of colloid cysts. The results showed that the average hospital stay following 

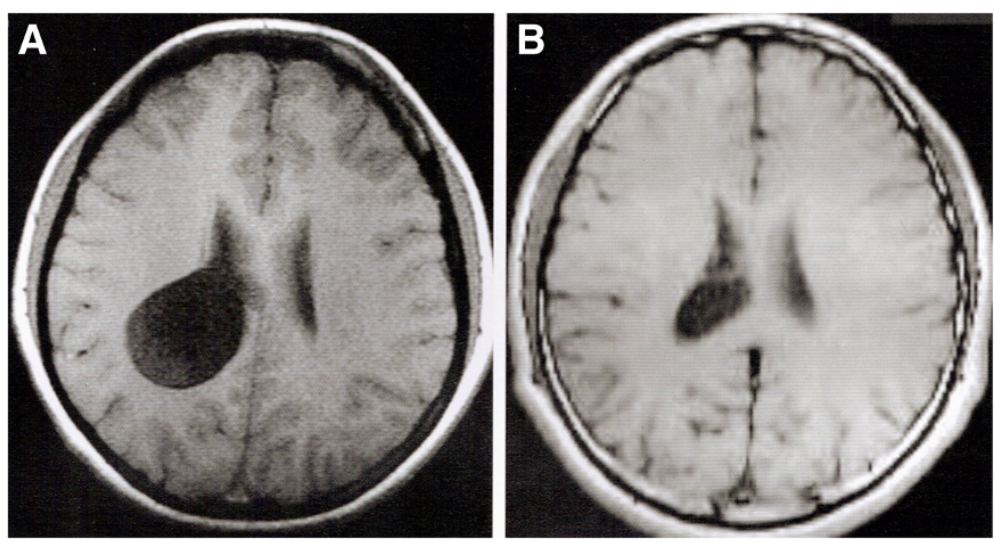

Figure 2 MR image of a cyst was diagnosed in the lateral ventricle (A) before operation and (B) follow-up 3-months after operation.

treatment of colloid cysts of the lateral and third ventricles by neuroendoscopy was 2.3 days compared to 5 days following craniotomy [8]. However, in our study, the length of hospital stay was the same for both the neuroendoscopy and non-neuroendoscopy groups (10 days).

The use of neuroendoscopy to treat intraventricular cysts is also associated with marked improvement in symptoms that include headache, nausea, vomiting, double vision, and paresis $[8,9,15]$. We found that the majority of patients (64.3\%) treated with neuroendoscopy had marked improvement in their symptoms, whereas only $5.1 \%$ of patients treated with a non-neuroendoscopy method had marked symptom improvement.

Many complications have been reported for nonneuroendoscopy and neuroendoscopy cyst treatment options. Complications of fenestration/resection and shunting procedures include meningitis, hemiparesis, oculomotor palsy, subdural hematomas, new epileptic seizure, hemorrhages, transient diabetes insipidus, psychosyndrome, and

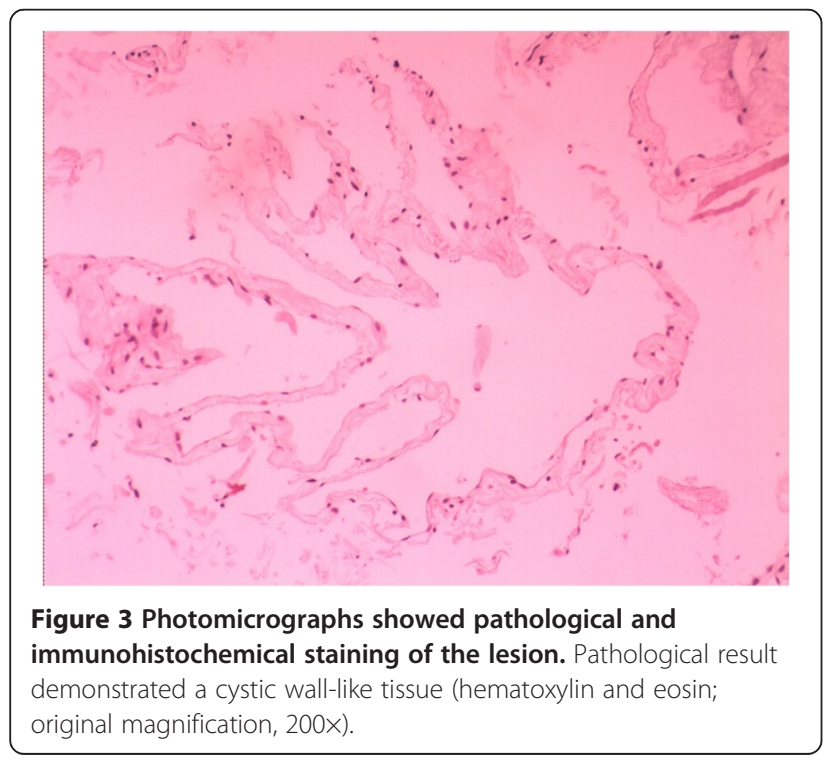

Table 2 Outcomes and complications between the 2 groups

\begin{tabular}{|c|c|c|c|}
\hline & $\begin{array}{l}\text { Neuroendoscopy } \\
\text { group }(n=28)\end{array}$ & $\begin{array}{c}\text { Non-neuroendoscopy } \\
\text { group }(n=39)\end{array}$ & P-value \\
\hline $\begin{array}{l}\text { Duration of } \\
\text { follow-up (year) }\end{array}$ & $2(2,4)$ & $2(2,3)$ & 0.330 \\
\hline $\begin{array}{l}\text { Alleviation of } \\
\text { symptoms, } \mathrm{n}(\%)^{2}\end{array}$ & & & $<0.001^{*}$ \\
\hline No effect & $2(7.1)$ & $13(33.3)$ & \\
\hline Improvement & $8(28.6)$ & $24(61.5)$ & \\
\hline $\begin{array}{l}\text { Marked } \\
\text { improvement }\end{array}$ & $18(64.3)$ & $2(5.1)$ & \\
\hline $\begin{array}{l}\text { Total effective } \\
\text { resection rate, } \\
\mathrm{n}(\%)^{2}\end{array}$ & $26(92.9)$ & $26(66.7)$ & $0.011^{*}$ \\
\hline Blood loss $(\mathrm{ml})^{1}$ & $50(50,100)$ & $200(200,300)$ & $<0.001^{*}$ \\
\hline $\begin{array}{l}\text { Hospitalization } \\
(\text { day })^{1}\end{array}$ & $10(12,15)$ & $10(10,40)$ & 0.596 \\
\hline $\begin{array}{l}\text { Operative time } \\
\text { (hour) }{ }^{1}\end{array}$ & $2(3,3)$ & $4(4,5)$ & $<0.001^{*}$ \\
\hline \multicolumn{4}{|l|}{$\begin{array}{l}\text { Complication, } \\
\mathrm{n}(\%)^{2}\end{array}$} \\
\hline Fever & $28(100)$ & $0(0.0)$ & $<0.001^{*}$ \\
\hline Subdural fluid & $8(28.6)$ & $0(0.0)$ & $<0.001^{*}$ \\
\hline $\begin{array}{l}\text { Subcutaneous } \\
\text { fluid }\end{array}$ & $4(14.3)$ & $1(2.6)$ & 0.152 \\
\hline Hydrocephalus & $0(0.0)$ & $7(17.9)$ & $0.036^{*}$ \\
\hline Infection & $0(0.0)$ & $1(2.6)$ & 1.000 \\
\hline $\begin{array}{l}\text { Intraventricular } \\
\text { hemorrhage }\end{array}$ & $0(0.0)$ & $3(5.8)$ & 0.506 \\
\hline Recurrence & $0(0.0)$ & $8(20.5)$ & $0.017^{*}$ \\
\hline
\end{tabular}

*Significant difference between the 2 groups, $\mathrm{P}<0.05$.

P-values are from ${ }^{1}$ Mann-Whitney $\mathrm{U}$ test and ${ }^{2}$ Chi-square test. Data are displayed as ${ }^{1}$ median (25th , 75th interquartile) and ${ }^{2}$ number (percentage). 
death [22,23]. In our study, neuroendoscopy compared with non-neuroendoscopy was associated with a greater proportion of patients having post-operative fever or subdural fluid accumulation. But these complications soon resolved.

Limitations of this study include its retrospective design and small sample size. Larger prospective studies are necessary to more fully compare the different methods for treating lateral ventricular cysts. Median follow-up duration was only 2 years; a longer follow-up period is needed for more complete assessment. This study also did not evaluate potential differences in the functional impairment of patients following neuroendoscopy versus non-neuroendoscopic surgery. This is of interest since a large trial $(\mathrm{N}=714)$ that assessed the clinical outcomes and quality-of-life of patients with ventricular and paraventricular cysts $(12.7 \%$ of whom had lateral ventricular cysts) found that the Karnofsky performance score significantly improved with neuroendoscopy (from 80 to $90 ; P<0.0001$ ) [9].

\section{Conclusion}

Minimally invasive neurosurgery is the standard technique for treating a number of neurological disorders. Neuroendoscopy is effective and relatively safe for treating patients with interventricular lesions. This is one of the first studies specifically designed to compare the efficacy and safety of neuroendoscopy with nonneuroendoscopic procedures for treating cysts located in the lateral ventricles. Our findings suggest that neuroendoscopy is effective for treating lateral ventricular cysts and in general resulted in better symptom relief and clinical outcomes than non-neuroendoscopic strategies.

\section{Consent}

Written informed consent was obtained from the patient for publication of this report and any accompanying images.

\section{Competing interest}

All authors have no competing interests.

\section{Authors' contributions}

YZ: guarantor of integrity of the entire study; study design; clinical studies; experimental studies; manuscript review. PZ: literature research; data acquisition; manuscript preparation; manuscript editing. XZ: study concepts; clinical studies; experimental studies. XW: definition of intellectual content; clinical studies; experimental studies. CL: data acquisition; data analysis. SG: data acquisition; statistical analysis. All authors have read and approved the final manuscript.

\section{Funding source}

This study is supported by the National Natural Science Fund of China (No. 30900342) and Beijing Nova program (2010B030).

\section{Author details}

'Department of Neurosurgery, Beijing Tiantan Hospital, Capital Medical University, Beijing 100050, People's Republic of China. ${ }^{2}$ Beijing Neurosurgical
Institute, Capital Medical University, Beijing 100050, People's Republic of China.

Received: 14 August 2012 Accepted: 22 May 2013

Published: 13 June 2013

References

1. Oertel JM, Baldauf J, Schroeder HW, Gaab MR: Endoscopic options in children: experience with 134 procedures. J Neurosurg Pediatr 2009, 3:81-89.

2. Tirakotai W, Schulte DM, Bauer BL, Bertalanffy H, Hellwig D: Neuroendoscopic surgery of intracranial cysts in adults. Childs Nerv Syst 2004, 20:842-851.

3. Badie B, Brooks N, Souweidane MM: Endoscopic and minimally invasive microsurgical approaches for treating brain tumor patients. J Neurooncol 2004, 69:209-219.

4. Nakase H, Hisanaga M, Hashimoto S, Imanishi M, Utsumi S: Intraventricular arachnoid cyst. Report of two cases. J Neurosurg 1988, 68:482-486.

5. Grondin RT, Hader W, MacRae ME, Hamilton MG: Endoscopic versus microsurgical resection of third ventricle colloid cysts. Can J Neurol Sci 2007, 34:197-207.

6. Lewis Al, Crone KR, Taha J, Van Loveren HR, Yeh HS, Tew JM Jr: Surgical resection of third ventricle colloid cysts. Preliminary results comparing transcallosal microsurgery with endoscopy. J Neurosurg 1994, 81:174-178.

7. Ahmad F, Sandberg Dl: Endoscopic management of intraventricular brain tumors in pediatric patients: a review of indications, techniques, and outcomes. J Child Neurol 2010, 25:359-367.

8. King WA, Ullman JS, Frazee JG, Post KD, Bergsneider M: Endoscopic resection of colloid cysts: surgical considerations using the rigid endoscope. Neurosurgery 1999, 44:1103-1109.

9. Hayashi N, Murai H, Ishihara S, Kitamura T, Miki T, Miwa T, Miyajima M, Nishiyama K, Ohira T, Ono S, Suzuki T, Takano S, Date I, Saeki N, Endo S: Nationwide investigation of the current status of therapeutic neuroendoscopy for ventricular and paraventricular tumors in Japan. J Neurosurg 2011, 115:1147-1157.

10. Maiuri F, laconetta G, Gangemi M: Arachnoid cyst of the lateral ventricle. Surg Neurol 1997, 48:401-404.

11. Osborn AG, Preece MT: Intracranial cysts: radiologic-pathologic correlation and imaging approach. Radiology 2006, 239:650-664.

12. Bergsneider M, Holly LT, Lee JH, King WA, Frazee JG: Endoscopic management of cysticercal cysts within the lateral and third ventricles. J Neurosurg 2000, 92:14-23.

13. Charalampaki P, Filippi R, Welschehold S, Conrad J, Perneczky A: Tumors of the lateral and third ventricle: removal under endoscope-assisted keyhole conditions. Neurosurgery 2008, 62:1049-1058.

14. Cinalli G, Cappabianca P, De Falco R, Spennato P, Cianciulli E, Cavallo LM, Esposito F, Ruggiero C, Maggi G, De Divitiis E: Current state and future development of intracranial neuroendoscopic surgery. Expert Rev Med Devices 2005, 2:351-373.

15. Hamada H, Hayashi N, Asahi T, Kurimoto M, Hirashima Y, Endo S: Efficacy of a navigation system in neuro-endoscopic surgery. Minim Invasive Neurosurg 2005, 48:197-201.

16. Westermaier T, Schweitzer T, Emestus Rl: Arachnoid cysts. Adv Exp Med Biol 2012, 724:37-50

17. El-Ghandour NM: Endoscopic treatment of middle cranial fossa arachnoid cysts in children. J Neurosurg Pediatr 2012, 9:231-238.

18. Boutarbouch M, El Ouahabi A, Rifi L: Management of intracranial arachnoid cysts: institutional experience with initial 32 cases and review of the literature. Clin Neurol Neurosurg 2008, 110:1-7.

19. Caemaert J, Abdullah J, Calliauw L, Carton D, Dhooge C, Van Coster R: Endoscopic treatment of suprasellar arachnoid cysts. Acta Neurochir (Wien) 1992, 119:68-73.

20. Elhammady MS, Bhatia S, Ragheb J: Endoscopic fenestration of middle fossa arachnoid cysts: a technical description and case series. Pediatr Neurosurg 2007, 43:209-215.

21. Gangemi M, Maiuri F, Colella G, Magro F: Endoscopic treatment of quadrigeminal cistern arachnoid cysts. Minim Invasive Neurosurg 2005, 48:289-292.

22. Schroeder HW, Gaab MR, Niendorf WR: Neuroendoscopic approach to arachnoid cysts. J Neurosurg 1996, 85:293-298.

23. Schroeder HW, Gaab MR: Endoscopic resection of colloid cysts. Neurosurgeny 2002, 51:1441-1444. 
24. Hopf NJ, Perneczky A: Endoscopic neurosurgery and endoscope-assisted microneurosurgery for the treatment of intracranial cysts. Neurosurgery 1998, 43:1330-1336.

25. Gangemi M, Seneca V, Colella G, Cioffi V, Imperato A, Maiuri F: Endoscopy versus microsurgical cyst excision and shunting for treating intracranial arachnoid cysts. J Neurosurg Pediatr 2011, 8:158-164.

26. Taniguchi M, Takimoto H, Yoshimine T, Shimada N, Miyao Y, Hirata M, Maruno M, Kato A, Kohmura E, Hayakawa T: Application of a rigid endoscope to the microsurgical management of 54 cerebral aneurysms: results in 48 patients. J Neurosurg 1999, 91:231-237.

27. Buxton N, Vloeberghs M, Punt J: Technical Note - Flexible neuroendoscopic treatment of supracellar arachnoid cysts. Brit J Neurosurg 1999, 13:316-318.

28. Yamamoto M, Oka K, lkeda K, Tomonaga M: Percutaneous flexible neuroendoscopic ventriculostomy in patients with shunt malfunction as an alternative procedure to shunt revision. Surg Neurol 1994, 42:218-223.

doi:10.1186/1471-2377-13-59

Cite this article as: Zhao et al:: The effectiveness of neuroendoscopic versus non-neuroendoscopic procedures in the treatment of lateral ventricular cysts: a retrospective medical record review study. BMC Neurology 2013 13:59.

\section{Submit your next manuscript to BioMed Central and take full advantage of:}

- Convenient online submission

- Thorough peer review

- No space constraints or color figure charges

- Immediate publication on acceptance

- Inclusion in PubMed, CAS, Scopus and Google Scholar

- Research which is freely available for redistribution 